\title{
4D dispersion of total gaseous mercury derived from a mining source: identification of criteria to assess risks related to high concentrations of atmospheric mercury
}

\author{
José M. Esbrí ${ }^{1}$, Pablo L. Higueras ${ }^{1}$, Alba Martínez-Coronado ${ }^{2}$, and Rocío Naharro ${ }^{1}$ \\ ${ }^{1}$ Instituto de Geología Aplicada, Castilla-La Mancha University, Almadén (Ciudad Real), 13400, Spain \\ ${ }^{2}$ Asociación española contra el Cáncer, Ciudad Real, 13002, Spain
}

Correspondence: José M. Esbrí (josemaria.esbri@uclm.es) and Pablo L. Higueras (pablo.higueras@uclm.es)

Received: 29 November 2019 - Discussion started: 13 March 2020

Revised: 15 September 2020 - Accepted: 23 September 2020 - Published: 6 November 2020

\begin{abstract}
Mercury $(\mathrm{Hg})$ is a global pollutant that can be transported long distances after its emission from primary sources. The most common problem of gaseous $\mathrm{Hg}$ in the vicinity of anthropogenic sources is its presence in inorganic forms and in the gaseous state in the atmosphere. Risk assessments related to the presence of gaseous $\mathrm{Hg}$ in the atmosphere at contaminated sites are often based on episodic and incomplete data, which do not properly characterize the $\mathrm{Hg}$ cycle in the area of interest or consider spatial or temporal terms. The aim of this work was to identify criteria to obtain the minimum amount of data with the maximum meaning and representativeness in order to delimit risk areas, both in a spatial and temporal respect. Data were acquired from May 2014 to August 2015 and included vertical and horizontal $\mathrm{Hg}$ measurements. A statistical analysis was carried out, and this included the construction of a model of vertical $\mathrm{Hg}$ movements that could be used to predict the location and timing of $\mathrm{Hg}$ inhalation risk. A monitoring strategy was designed in order to identify the relevant criteria, and this involved the measurement of gaseous $\mathrm{Hg}$ in a vertical section at low altitude (i.e. where humans are present) and in horizontal transects to appropriately characterize the transport cycle of gaseous $\mathrm{Hg}$ in the lower layers of the atmosphere. The measurements were carried out over time in order to obtain information on daily and seasonal variability. The study site selected was Almadenejos (Ciudad Real, Spain), a village polluted with mercury related to decommissioned mining and metallurgical facilities belonging to the Almadén mercury mining district.
\end{abstract}

The vertical profiles revealed that higher total gaseous mercury concentrations are present at lower altitude during nocturnal hours and at higher altitude at dawn and dusk. On a daily basis the most important process involved in gaseous mercury movements is the mixing layer. Vertical transferences are predominant when this process is active, i.e. in all seasons except winter, while major sources act as constant suppliers of gaseous $\mathrm{Hg}$ to the mixing cell, thus producing $\mathrm{Hg}$ deposition at dusk. Conversely, horizontal transferences prevail during the hours of darkness and the main factors are major and minor sources, solar radiation, wind speed, and topography. The study has shown that it is important (i) to identify the sources, (ii) to get data about $\mathrm{Hg}$ movements in vertical and horizontal directions, (iii) to extend the measurements over time in a sufficiently representative way both daily and seasonally, and (iv) to determine the different populations of data to establish the background levels; this work proposes the use of Lepeltier graphs to do so.

In terms of risk assessment, the nights carry greater risk than the days in all seasons except autumn. The main factors involved in the creation of high-risk periods are those related to dilution (or its absence), namely wind speed and solar radiation at null levels.

The results of this study highlight the possible importance of relieving the distribution of gaseous mercury in proximity to discrete sources. Furthermore, systematic monitoring strategies can offer significant information for the Minamata Convention emission reduction scenario. Further studies, including a detailed topographic model of the area, are required in order to make precise estimations of the influence of this 
parameter, which appears in this study to be less important than the other factors but is still appreciable.

\section{Introduction}

Mercury $(\mathrm{Hg})$ is considered to be a global pollutant due to its ability to be transferred between different environmental compartments and over long distances, which results in the contamination of pristine areas far from the sources. The $\mathrm{Hg}$ cycle in the environment begins with geogenic or anthropogenic emissions, which mainly consist of gaseous elemental mercury (GEM) along with minor proportions of particle-bound mercury (PBM) and reactive gaseous mercury (RGM). GEM and RGM species constitute "total gaseous mercury" (TGM). The residence time of each of these mercury species is different and is much longer for GEM, which means that this species can be deposited in remote areas such as the Arctic Sea, while PBM and RGM are often deposited nearer to the source (Radke et al., 2007, and references therein). Once $\mathrm{Hg}$ has been deposited, a cycle of reemission-deposition, along with changes in $\mathrm{Hg}$ speciation, explains the flows of this element in the environment.

Numerous $\mathrm{Hg}$ transfer pathways are involved in this cycle, and these include soil-atmosphere, soil-plant, plant-atmosphere, water-atmosphere and sediment-water, amongst others. These fluxes have been quantified by different approaches, most of which employ dynamic flow chambers, micrometeorological methods and bulk methods (Carpi and Lindberg, 1997; O'Driscoll et al., 2003; Stamenkovic et al., 2008; Eckley et al., 2011; Zhu et al., 2015; Fu et al., 2016; Zhu et al., 2016, amongst others). Results show that processes of $\mathrm{Hg}$ deposition and emission are included in a complex cycle with a large number of factors involved, mainly seasonality, vegetation coverage, temperature, solar radiation, relative humidity, diurnal atmospheric turbulence and the presence of $\mathrm{Hg}$ oxidants (Zhu et al., 2016). A maximum emission during diurnal hours was described for soils (Zhu et al., 2015), mine materials (Eckley et al., 2011), water (O’Driscoll et al., 2003), sediments (Sizmur et al., 2017) and snow (Maxwell et al., 2013), while forb leaf (Stamenkovic et al., 2008) and growing broad leaf (Fu et al., 2016) reach their minimum emission rates during diurnal hours. These daily cycles of $\mathrm{Hg}$ emissions from soils, water or plants contribute to the increase in the atmospheric mercury pool, especially in the lower layers of the troposphere. Most of the available information on this topic is on a scale of kilometres at high altitudes in the range 500-11000 $\mathrm{m}$ from background and contaminated locations (Slemr et al., 2018; Weigelt et al., 2016); however, information about TGM dispersion on a scale of metres is scarce. Some information about these distances comes from episodic monitoring by means of lidar techniques, such as those measured in China, where maximum levels at lower altitudes were detected during night- time hours (Guan et al., 2010). Saiz-Lopez et al. (2008) modelled the vertical profile of GEM over Antarctica and found that maximum levels were located at lower altitudes during daytime hours. Tackett et al. (2007) described a vertical GEM profile in the Arctic troposphere and found maximum levels of GEM at heights of $20-80 \mathrm{~m}$ above the ground under different conditions. Steffen et al. (2002) studied vertical profiles on snowpack before and during depletion events and found that GEM levels increased sharply at the surface during the depletion event on a $2 \mathrm{~m}$ profile. Ferrara et al. (1998) identified higher TGM concentrations a few centimetres above the ground and background values at heights $10-20 \mathrm{~m}$ above the ground at the eastern border of Almadén village.

Risk assessments of areas with anthropogenic contamination of gaseous $\mathrm{Hg}$ are often carried out with scarce data, often corresponding to short periods of time. These do not provide a representative view of the day-night contrast or the seasonality, not even at the level of hot and cold or dry and wet seasons (depending on the location of the case study). We have conducted studies based on sampling times selected in the worst theoretical conditions, with higher expected emission rates enhanced by temperature and solar radiation, with the aim of identifying the worst-case scenario in summer days without winds at a mining site in Almadén (Martinez-Coronado et al., 2011), in a mining complex at Mount Amiata in Italy (Vaselli et al., 2013), in a chloralkali plant in Tarragona (Esbrí et al., 2015), in a chloralkali plant in Romania (Esbrí et al., 2018a), and in a period of time with more $\mathrm{Hg}$ metallurgical works in Almadén (Tejero et al., 2015); this includes the evaluation of background conditions (Higueras et al., 2014) and comparison of the worst and best scenarios (Higueras et al., 2013). However, we realized that the mercury cycles at all of the studied sites were not exactly the same and that the most important factors that control the emission, transport and deposition processes also differed from one area to another. This idea can be exemplified by the most recent reference found for risk assessment related to gaseous mercury (Deng et al., 2016). Deng et al. (2016) found correlations between methylmercury ( $\mathrm{MeHg}$ ) in blood and TGM in the air after only seven gaseous $\mathrm{Hg}$ measurements without covering a full annual period. There are many confounding variables that may produce this correlation due to the low representativeness of gaseous $\mathrm{Hg}$ sampling. It therefore seems necessary to carry out a sufficiently representative sampling in order to understand the peculiarities of the $\mathrm{Hg}$ cycle in the study area to achieve a realistic risk assessment. In this sense, it is necessary to gain knowledge of $\mathrm{Hg}$ flows from the moment that it is emitted and to understand the main mechanisms of dilution and/or concentration. It is also necessary to obtain information on the evolution in the vertical direction with respect to the source and also horizontally, as this information will provide the dispersion of the contaminant in the area. It is also highly recommended to obtain information on the temporal evolution of these vertical and horizontal processes, both daily and sea- 
sonally. These objectives can be sufficiently accomplished using passive samples (McLagan et al., 2018), with the clear advantages of low cost and easier application, especially in areas with access difficulties. Some uncertainties remain in this approach, the most important being the $\mathrm{Hg}$ compounds that these passive samplers uptake. This uncertainty can be important in the vicinity of industrial sites (for instance, chloralkali plants), where RGM can be in higher proportions.

The main objective of the work described here was to obtain information on vertical and horizontal profiles of TGM in an environment contaminated by decommissioned mercury mining facilities, with the ultimate objective of locating the risk areas around the main sources of emissions and the moment at which the risk in these areas was significant. Data acquisition was carried out over a whole year in order to identify relationships between TGM data and secular variations in local micrometeorological and topographical data.

\section{Methodology}

In this work we have tried to obtain the minimum information necessary about the emission, transport and deposition of atmospheric mercury to ensure the representativeness of such data with a minimum cost in terms of effort and money. Before determining the sampling locations, an exhaustive identification of the Almadenejos emission sources, represented in red in Fig. 1, was carried out with a Lumex RA915M in mobile monitoring mode using a car to cover the entire area. In the town centre of Almadenejos there are four emission sources of medium importance (cinnabar waste), while in the vicinity there is one of very high importance (a mining and metallurgical precinct - MMP), one of high importance (Nueva Concepción mine) and two of low importance (a contaminated road running north of the town and the course of the Valdeazogues River, since it passes through the El Entredicho mine). The importance of the sources has been established if the average concentrations are below $200 \mathrm{ng} \mathrm{m}^{-3}$ (low importance), in the range of 200$1000 \mathrm{ng} \mathrm{m}^{-3}$ (medium importance) or up to $1000 \mathrm{ng} \mathrm{m}^{-3}$ (high importance).

In an effort to achieve the main objective of this work, it was decided to obtain data in the three directions of space, including a short vertical transect and long horizontal transects that include emission sources of high, medium and low importance. These data were also obtained serially over time to cover both the daytime cycles of light and darkness, as well as the seasonal cycles of hot and cold periods.

\subsection{Vertical profile measurements}

Total gaseous mercury (TGM) was measured at a site located in proximity to Almadenejos village (Fig. 1) and corresponding to a closed precinct that encompasses the Almadenejos wastewater treatment plant (AWTP) (WGS84; $30 \mathrm{~m} \mathrm{~S}$,
$351707 \mathrm{~m} \mathrm{E}, 4289235 \mathrm{~m} \mathrm{~N}$ ). Almadenejos was a secondary mining and metallurgical centre in the so-called Almadén mercury mining district (Higueras et al., 2006). This area includes three large mines, which are now closed, and a metallurgical precinct located immediately to the north of the urban area representing the only significant active local source of gaseous mercury (Martínez-Coronado et al., 2011). This is an excellent area for the study of $\mathrm{Hg}$ transference between environmental compartments (Naharro et al., 2018; Campos et al., 2018) due to scarce remediation work that has been carried out in recent centuries, which has left a legacy of anomalous $\mathrm{Hg}$ presence in the soils, roads and rivers. Previous data on PBM from the area have shown that emissions are related to the creation of a diurnal mixing layer, while dry deposition rates $\left(317 \mu \mathrm{g} \mathrm{m}^{-2} \mathrm{yr}^{-1}\right)$ were of the order of other rural areas and lower than urban areas (Esbrí et al., 2018b).

The equipment used to make the measurements was a Tekran 2537B with a synchronized multi-port sampler (model 1115) that allowed alternate measurement of up to six separate input streams. In this work only three of these six sampling possibilities were used, and these corresponded to sampling points located at $0.5,2$ and $3 \mathrm{~m}$ above the ground, with measurements made from September 2014 to August 2015. An external pump working at $15 \mathrm{~m}^{3} \mathrm{~h}^{-1}$ was employed, with the sampling lines purged with $\mathrm{Hg}$-free air $\left(\mathrm{GEM}<2 \mathrm{ng} \mathrm{m}^{-3}\right)$ when not in use. Various gradients were used in order to study differences in TGM contents at different altitudes: total gradient $\left(\mathrm{TGM}_{3 \mathrm{~m}}-\mathrm{TGM}_{0.5 \mathrm{~m}}\right)$, lower gradient $\left(\mathrm{TGM}_{3 \mathrm{~m}}-\mathrm{TGM}_{2 \mathrm{~m}}\right)$ and upper gradient $\left(\mathrm{TGM}_{2 \mathrm{~m}}{ }^{-}\right.$ $\left.\mathrm{TGM}_{0.5 \mathrm{~m}}\right)$.

The device was calibrated every $7 \mathrm{~d}$ by means of an internal permeation source. An intercomparison exercise between Lumex RA-915M and Tekran 2537B systems was carried out in 2011 in conjunction with the Spanish Instituto de Salud Carlos III, and a compatibility index (see ISO/IEC, 1997) of less than 1 was found during all experiments (FernándezPatier and Ramos-Díaz, 2011).

Micrometeorological data were acquired using a Davis Vantage Pro meteorological station, which is a fully automated device that allows data to be collected every $15 \mathrm{~min}$, including temperature, relative humidity, wind speed and direction, atmospheric pressure, rain, solar radiation, and ultraviolet radiation. The location of this device (WGS84; $30 \mathrm{~m} \mathrm{~S}$, $351714 \mathrm{~m} \mathrm{E}, 4289255 \mathrm{~m} \mathrm{~N}$ ) is shown in Fig. 1 at the AWTP in Almadenejos.

\subsection{Horizontal profile measurements}

The sampling strategy was designed to cover not only anomalous GEM data from local emission sources, but also background GEM data around major and minor sources at locations far from Almadenejos. As shown in Fig. 1, three transects were chosen to achieve these objectives.

- Profile 1 has a length of $12350 \mathrm{~m}$, including two crosscuts with the Valdeazogues River, which transports 


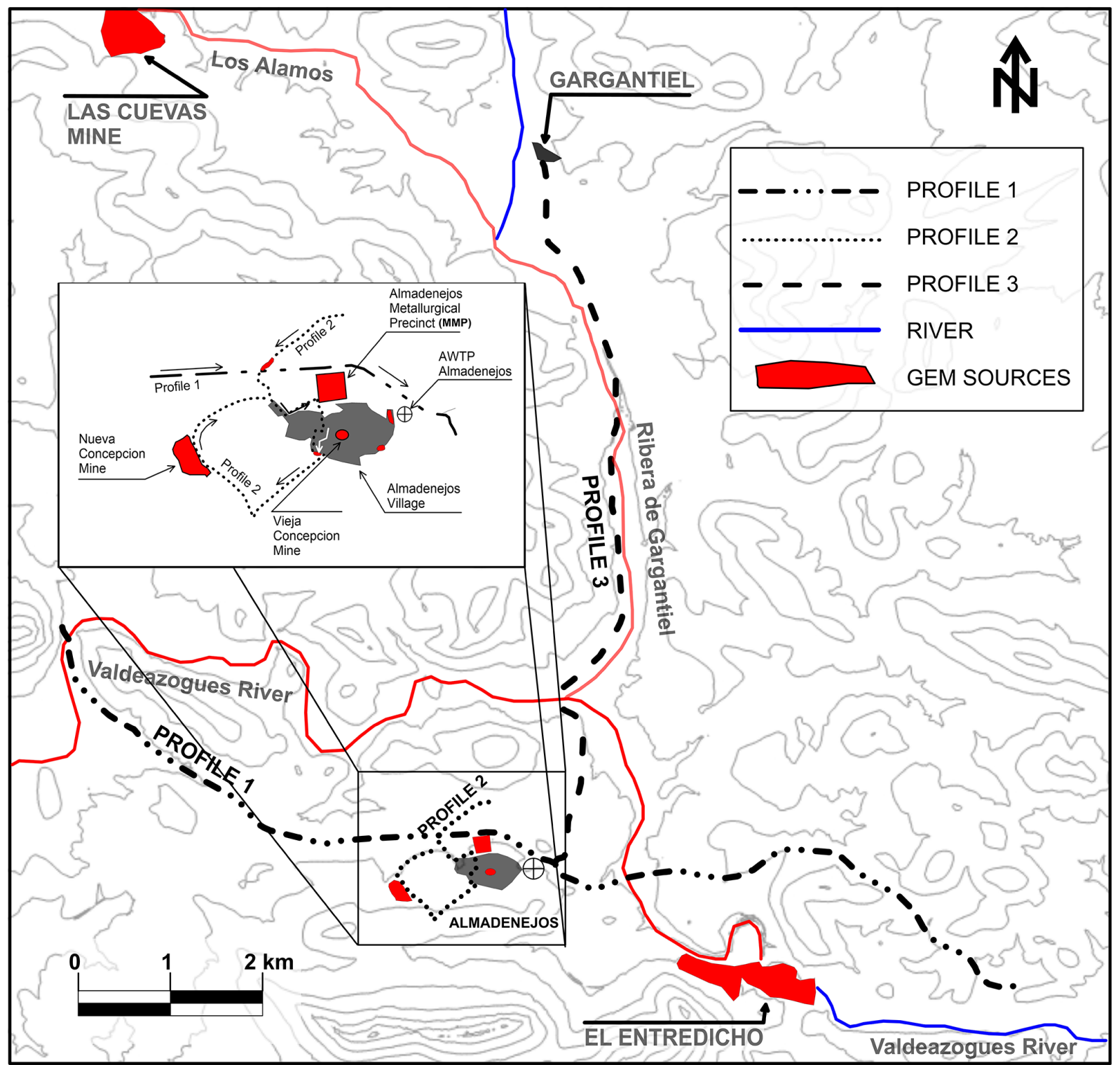

Figure 1. Location of the three horizontal profiles in the study area and main mercury mining sites. AWTP: Almadenejos wastewater treatment plant. Main known gaseous mercury sources are shown in red (including rivers with Hg-contaminated sediments); uncontaminated streams are shown in blue.

sediments moderately contaminated with $\mathrm{Hg}$ (GarcíaOrdiales et al., 2016), especially in the vicinity of the El Entredicho open-pit mine (Fig. 1). This profile passes close to Almadenejos village, $40 \mathrm{~m}$ from the main GEM source in the studied area, which is a decommissioned mining and metallurgical plant (MMP) (Martínez-Coronado et al., 2011). This profile was selected with the aim of identifying relationships between background GEM data at large distances from Almadenejos and local anomalous GEM data from the main source area.
- Profile 2 has a length of $3650 \mathrm{~m}$ and it cross-cuts the main GEM sources of the village: La Nueva Concepción mine, MMP and two minor GEM sources in tracks paved with contaminated materials from the MMP. This profile was selected with the aim of identifying possible relationships between anomalous GEM data from local sources and background data from the hills located to the south and north of Almadenejos.

- Profile 3 covers $8450 \mathrm{~m}$ from the Almadenejos village limits to the village of Gargantiel. This profile mainly represents the background values, including a cross-cut over two minor GEM sources of polluted sediments: 
the Valdeazogues River and its tributary, the Gargantiel River.

Data acquisition on GEM was performed using a Lumex RA915M device, which is a portable atomic absorption spectrometer that is able to collect one GEM data point every second (Higueras et al., 2014). The device was installed on an automobile, with the sampling line located on the front side of the vehicle. The speed was kept constant during the sampling time, i.e. in the range $40-50 \mathrm{~km} \mathrm{~h}^{-1}$. Baseline checks were carried out at the beginning and the end of each profile, and a baseline correction was performed when differences were up to $1 \mathrm{ng} \mathrm{m}^{-3}$, assuming that the lamp variation was linear during measurements. Data acquisition was carried out during 24 different days for profile 1,29 for profile 2 and 27 for profile 3 during the period May 2014 to June 2015. Monitoring days included two meteorological conditions: days with calm winds and days with regional winds. The profiles had differences in the number of data points and precise locations along the profile. In order to enable direct comparison of the collected data and to minimize erraticism, an average for each $100 \mathrm{~m}$ was calculated, and each average was assigned to the centre of the corresponding distance range.

\subsection{Statistical treatment}

Data analysis was carried out with different software packages: Microsoft Excel, Minitab 15 and Golden Surfer 9. A multiple linear regression analysis (MLRA) on the normalized dataset of vertical profiles was performed using Minitab 15. A best subset regression analysis was performed using Mallows' CP to identify the best predictors prior to performing a multiple linear regression analysis on each dataset. A fitted line graph was constructed using the equation obtained in the MLRA to obtain an $R^{2}$ value based on a new equation between the measured gradient (or TGM) and predicted gradient. Lepeltier graphs were used to find the distribution pattern that best fitted the various sets of GEM data in horizontal profiles. A lognormal distribution curve (Lepeltier, 1969) is defined by two parameters: one is dependent on the mean value and the other is dependent on the character of the distribution of values. These parameters were determined graphically by means of cumulative frequency curves in log-probability plots using Minitab 15. Finally, the delimitation maps of risk areas due to the presence of gaseous $\mathrm{Hg}$ were produced using Surfer 9.

\section{Results and discussion}

\subsection{Vertical profiles}

The daily evolution pattern of TGM (Fig. 2) is similar to that described by Esbrí et al. (2016) for Almadén, which is located $11 \mathrm{~km}$ to the west of Almadenejos: the pattern shows low TGM levels during diurnal hours and higher lev-
Table 1. Statistical summary of TGM levels at different heights (3, 2 and $0.5 \mathrm{~m})$ and total gradient $(3-0.5 \mathrm{~m})$, upper gradient $(3-2 \mathrm{~m})$ and lower gradient $(2-0.5 \mathrm{~m})$ at the Almadenejos WWTP. All TGM data are in nanograms per cubic metre $\left(\mathrm{ng} \mathrm{m}^{-3}\right)$.

\begin{tabular}{|c|c|c|c|c|}
\hline & $N$ & Maximum & Minimum & Average \\
\hline \multicolumn{5}{|l|}{ All data } \\
\hline TGM (3 m) & 6518 & 3012 & 2 & 125 \\
\hline TGM (2 m) & 6518 & 2807 & 1 & 111 \\
\hline TGM (0.5 m) & 6510 & 1971 & 1 & 102 \\
\hline \multicolumn{5}{|l|}{ Autumn } \\
\hline TGM (3 m) & 1570 & 2378 & 2 & 134 \\
\hline TGM (2 m) & 1570 & 1544 & 1 & 116 \\
\hline TGM $(0.5 \mathrm{~m})$ & 1570 & 1360 & 1 & 104 \\
\hline \multicolumn{5}{|l|}{ Winter } \\
\hline TGM (3 m) & 1222 & 1056 & 5 & 93 \\
\hline TGM (2 m) & 1222 & 813 & 5 & 79 \\
\hline TGM $(0.5 \mathrm{~m})$ & 1221 & 525 & 4 & 70 \\
\hline \multicolumn{5}{|l|}{ Spring } \\
\hline TGM (3 m) & 1589 & 1506 & 7 & 93 \\
\hline TGM (2 m) & 1589 & 837 & 5 & 80 \\
\hline TGM $(0.5 \mathrm{~m})$ & 1582 & 819 & 4 & 75 \\
\hline \multicolumn{5}{|l|}{ Summer } \\
\hline TGM (3 m) & 2137 & 3012 & 7 & 160 \\
\hline TGM (2 m) & 2137 & 2807 & 7 & 147 \\
\hline TGM $(0.5 \mathrm{~m})$ & 2137 & 1971 & 7 & 137 \\
\hline \multicolumn{5}{|c|}{ Almadén (Esbrí et al., 2016) } \\
\hline TGM Autumn & 2025 & 281 & 0.8 & 23 \\
\hline TGM Winter & 1159 & 122 & 0.8 & 13 \\
\hline TGM Spring & 1067 & 280 & 3.1 & 23 \\
\hline TGM Summer & 2019 & 687 & 2.5 & 52 \\
\hline
\end{tabular}

els during the rest of the day, a finding that has been interpreted as being due to a decrease in the wind speed during the night (Fig. 2). In terms of TGM levels (see Table 1 and Fig. 2 for more details), the site studied in Almadenejos has TGM concentrations that are at least 3 times higher than those measured at the Almadén site described by Esbrí et al. (2016), and a more marked difference between maximum and minimum daily TGM concentrations was observed. This behaviour is probably due to the fact that in Almadén the main dump was reclaimed during the years 20082010, which led to a very significant decrease in local TGM (Higueras et al., 2013), whereas reclamation of the metallurgical precinct has never been performed in Almadenejos. As a result, a huge amount of metallurgical waste remains in the MMP (Martinez-Coronado et al., 2011), in addition to the presence of some minor sources produced by the network of roads and tracks or uncontrolled accumulation of contaminated waste (Fig. 1). Seasonally, the main pattern is similar 
Table 2. Statistical summary of gradients: total gradient $(3-0.5 \mathrm{~m})$, upper gradient (3-2 m) and lower gradient (2-0.5 m). All TGM data are in nanograms per cubic metre $\left(\mathrm{ng} \mathrm{m}^{-3}\right)$.

\begin{tabular}{lrrrr}
\hline & $N$ & Maximum & Minimum & Average \\
\hline All data & & & & \\
\hline Gradient (3-0.5 m) & 6510 & 398 & -1270 & -23 \\
Gradient (3-2 m) & 6510 & 578 & -1066 & -9 \\
Gradient (2-0.5 m) & 6518 & 566 & -1280 & -14 \\
\hline Autumn & & & & \\
\hline Gradient (3-0.5 m) & 1570 & 398 & -1166 & -30 \\
Gradient (3-2 m) & 1570 & 578 & -756 & -12 \\
Gradient (2-0.5 m) & 1570 & 566 & -1280 & -18 \\
\hline Winter & & & & \\
\hline Gradient (3-0.5 m) & 1221 & 164 & -531 & -23 \\
Gradient (3-2 m) & 1221 & 160 & -484 & -9 \\
Gradient (2-0.5 m) & 1222 & 468 & -400 & -14 \\
\hline Spring & & & & \\
\hline Gradient (3-0.5 m) & 1582 & 171 & -691 & -18 \\
Gradient (3-2 m) & 1582 & 263 & -559 & -6 \\
Gradient (2-0.5 m) & 1589 & 149 & -789 & -12 \\
\hline Summer & & & & -13 \\
\hline Gradient (3-0.5 m) & 2137 & 371 & -1270 & -22 \\
Gradient (3-2 m) & 2137 & 433 & -1066 & -10 \\
Gradient (2-0.5 m) & 2137 & 318 & -801 & -13 \\
\hline
\end{tabular}

to that described by Esbrí et al. (2016) in the nearby town of Almadén, with lower TGM levels in winter and higher levels in summer. However, transitional seasons show a different trend, especially in springtime, when TGM levels are at an intermediate level between winter and autumn.

Vertical gradients at the AWTP (Table 2 and Fig. 2) show TGM concentrations that are lower during diurnal and windy hours, with higher concentrations at lower heights above the ground in all three sections considered $(3-0.5 ; 3-2 ; 2-0.5)$. Variability according to season does not appear to have any evident pattern, except for summer versus autumn, winter and spring: summer data reached positive levels only in the first few hours before and after the atmospheric mixing process was active, i.e. at dawn and dusk, especially for gradients $3-0.5$ and $2-0.5$. These positive differences between heights in terms of TGM suggest that mercury can remain accumulated at lower heights during the night, rising while the mixing layer is being created and falling when this mixing layer disappears. These data could indicate that a diurnal cycle of emission and deposition could be active in the studied area and that deposition is intense - especially at dusk - in the transitional hours between higher and lower winds. Llanos et al. (2011) estimated the annual emissions of the MMP to be $16.4 \mathrm{~kg} \mathrm{yr}^{-1}$, but the dispersion-dilution process of these emissions in the surrounding environment was un- known and it was impossible to perform a similar measurement with a crane over this MMP facility.

The daily evolution of the maximum, medium and minimum values for each of the three heights monitored is represented in Fig. 3, with the aim of visualizing the vertical movements of $\mathrm{Hg}$ and the heights at which they occur, both ascending and descending. It can be observed that in the summer the flows in the highest monitored sector occur only in the early hours of the morning, thus precluding the movement of $\mathrm{Hg}$ from the lowest to the highest monitored height. Instead, the exchange in the lower part is continuous throughout the day, i.e. from dawn to dusk. This phenomenon must be due to the confluence of three micrometeorological factors: high temperatures and solar radiation coincidental with low relative humidity values, which combine to increase the intensity of the formation of the mixing layer during the day; this has the consequence of an increment of wind speed in the investigated area. In spring a similar exchange of maximum and minimum values also occurs early in the day, but in this case the exchange is maintained throughout the day only in the highest monitored sector. The main difference between these two seasons is the soil temperature, which is much lower in spring $\left(16^{\circ} \mathrm{C}\right)$ than in summer $\left(27^{\circ} \mathrm{C}\right)$. In the spring, the lower soil temperature would promote a thinner mixing layer, which would be unable to promote $\mathrm{Hg}$ transfers in the region close to the ground, while in summer the high ambient and soil temperatures would increase the thickness of the mixing layer, thus producing $\mathrm{Hg}$ transfers in lower areas. Autumn, the other transition season, shows flows in the upper sector during the day and in the lower part only at dawn when wind has ceased. Finally, in winter, when micrometeorological factors attenuate the creation of the mixing layer, flows were not detected during the day and only at dusk was a single exchange in the upper part of the monitored sectors measurable.

The evolution of the TGM gradient during a typical summer day (with symmetrical temperature and solar radiation profiles during daytime hours) exemplifies this process perfectly (Fig. 4a), with positive gradients observed as solar radiation declined and an increase in the early morning. Negative gradients were observed during night-time hours, probably as a consequence of the stratification of lower atmospheric layers when the wind speed was zero or close to zero. A similar trend was observed on a winter day (Fig. 4b) and on a day with thermal inversion in the morning (Fig. 4c), but this tendency was not observed during rainy periods, such as a rainy day in November (Fig. 4d), on windy days (Fig. 4e) or on misty days (Fig. 4f).

On considering the weight of each factor by applying a multiple linear regression analysis (Table 3), it was observed that solar radiation is the key factor in spring, autumn and winter, but wind speed can better explain gradient data in summer. Surprisingly, temperature appears to be a secondary factor in all seasons, and only in the summer period and in the lower gradient does this appear to be an important factor. 

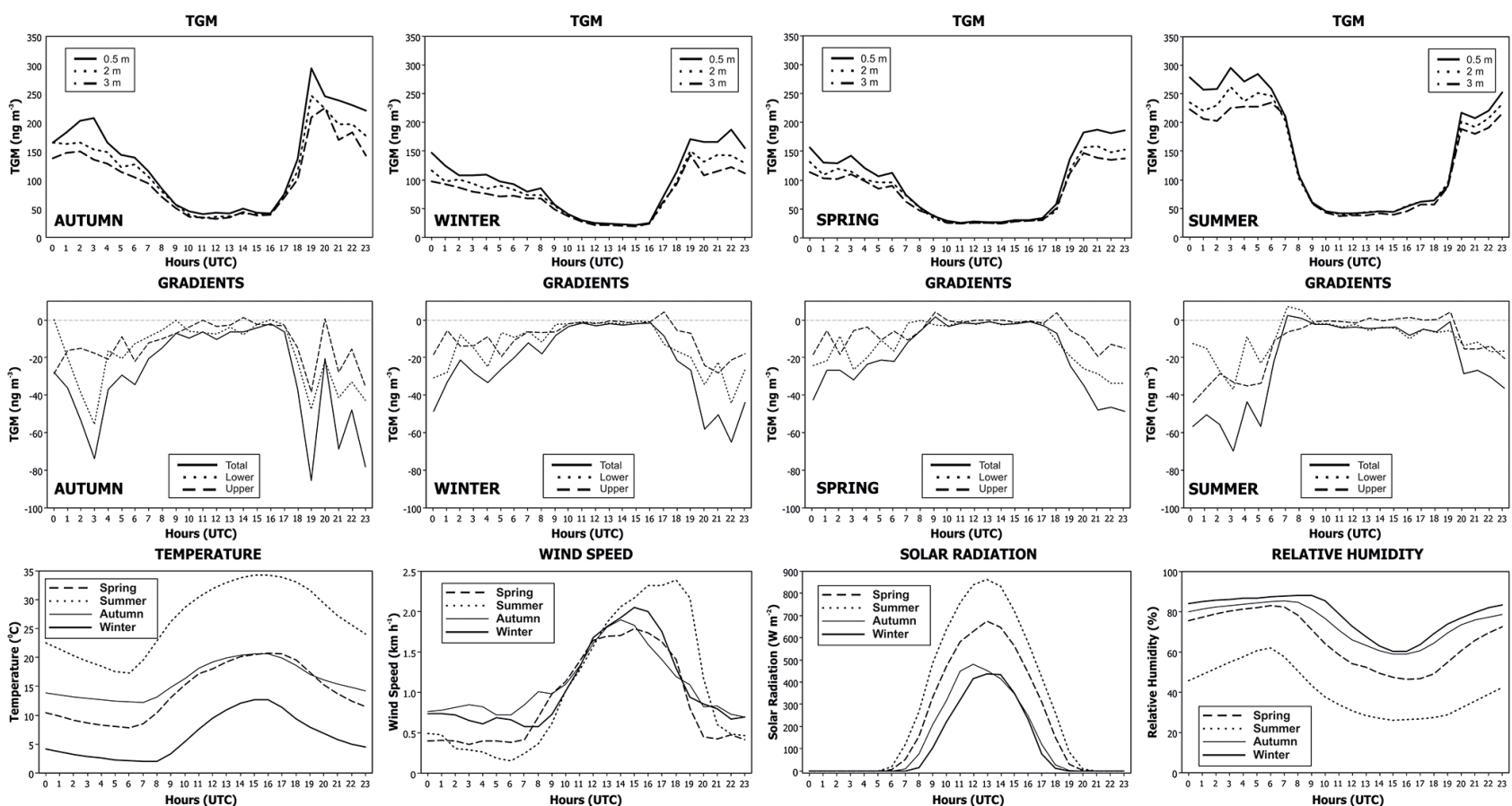

Figure 2. Daily and seasonal evolution of TGM contents at 3,2 and $0.5 \mathrm{~m}$ above the ground at the AWTP site (upper row); daily and seasonal evolution of gradients at 3-0.5, 3-2 and 2-0.5 m above the ground at the AWTP site (middle row); and daily and seasonal evolution of micrometeorological parameters (temperature, solar radiation, relative humidity and wind speed) at the AWTP site (lower row).
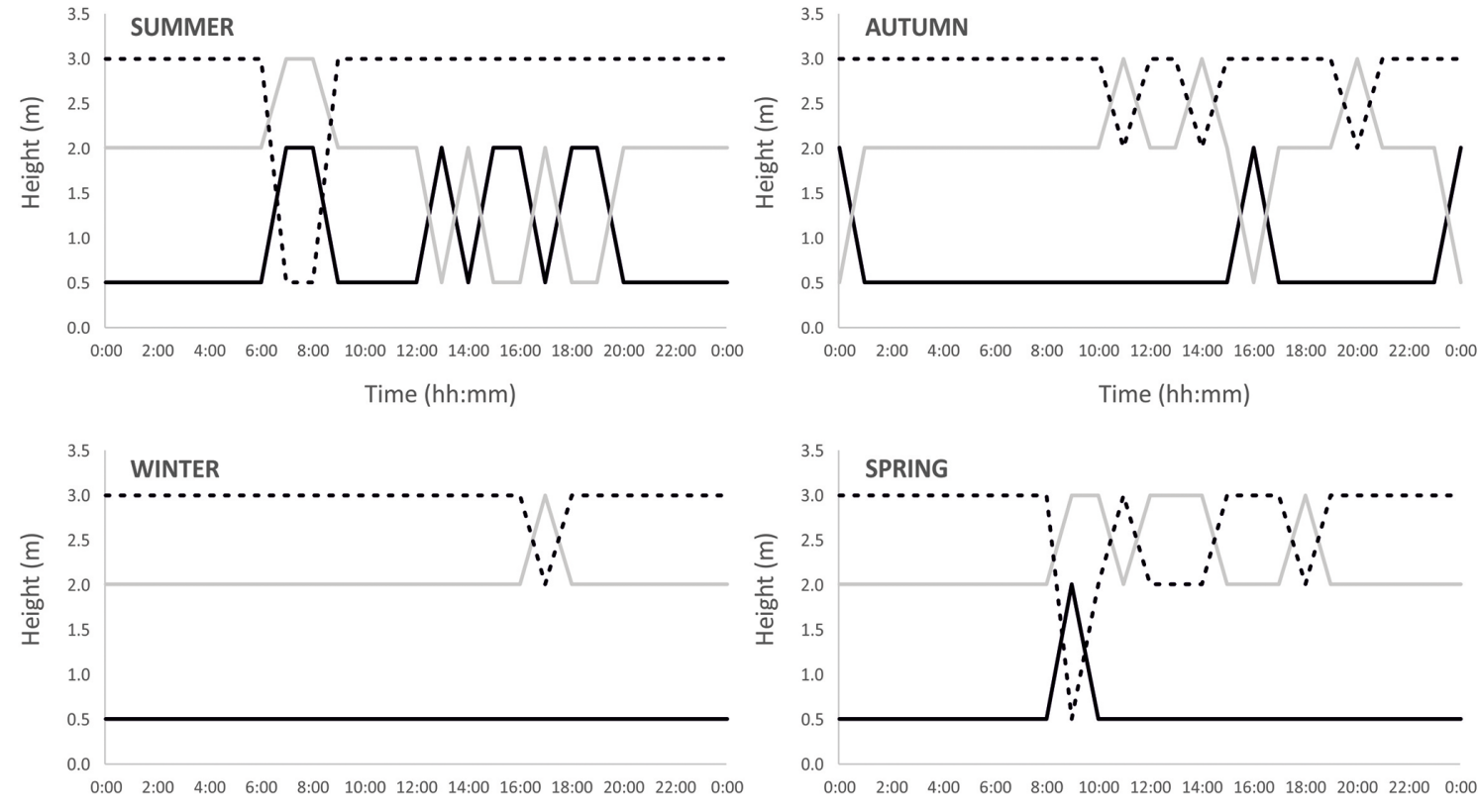

Time (hh:mm)

Time (hh:mm)

High TGM

- Medium TGM

- - Low TGM

Figure 3. Schematic representation of the daily evolution of the maximum, medium and minimum levels of gaseous $\mathrm{Hg}$ at the three measuring points in the vertical profile. 


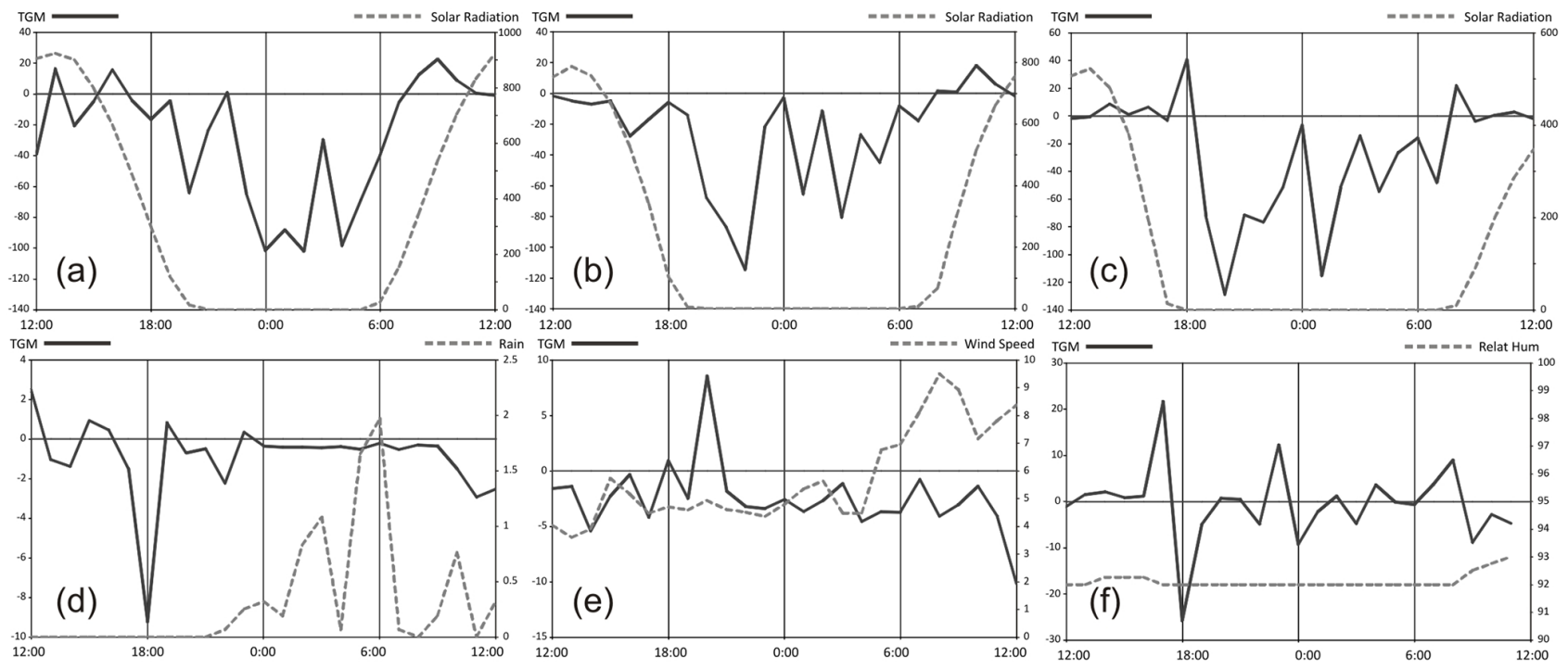

Figure 4. Evolution of TGM total gradients during typical contrasting meteorological conditions: (a) typical summer day; (b) typical winter day; (c) thermal inversion day; (d) rainy day; (e) windy day; and (f) foggy day.

Table 3. Predictor coefficients resulting from a multiple linear regression analysis (MLRA). The main predictors by season are shown in bold type. Abbreviations: Temp: outside temperature; Hum: outside humidity; WindSp.: wind speed; BarPres: barometric pressure; SolarRad.: solar radiation; n.c.: not considered in the MLRA.

\begin{tabular}{|c|c|c|c|c|c|c|c|c|}
\hline & Constant & Temp & Hum & WindSp & BarPres & Rain & SolarRad & $r^{2}$ \\
\hline \multicolumn{9}{|l|}{ Grad. tot } \\
\hline Summer & 0.010 & 0.112 & n.c. & 0.143 & 0.034 & -0.022 & 0.079 & 57.4 \\
\hline Spring & 0.001 & n.c. & 0.087 & 0.161 & -0.047 & 0.015 & 0.215 & 77.6 \\
\hline Autumn & 0.000 & -0.068 & 0.043 & 0.164 & -0.101 & n.c. & 0.175 & 83.9 \\
\hline Winter & 0.001 & 0.127 & 0.092 & 0.165 & n.c. & 0.036 & 0.172 & 74.8 \\
\hline \multicolumn{9}{|l|}{ Grad. inf. } \\
\hline Summer & 0.008 & 0.101 & -0.021 & 0.1 & -0.001 & n.c. & 0.056 & 85.8 \\
\hline Spring & 0.002 & n.c. & 0.063 & 0.133 & -0.037 & 0.013 & 0.156 & 85.0 \\
\hline Autumn & 0.000 & -0.072 & n.c. & 0.114 & -0.054 & n.c. & 0.112 & 91.5 \\
\hline Winter & 0.000 & 0.083 & 0.091 & 0.117 & -0.045 & n.c. & 0.144 & 84.3 \\
\hline \multicolumn{9}{|c|}{ Grad. sup. } \\
\hline Summer & 0.014 & 0.001 & n.c. & 0.07 & 0.015 & 0.002 & 0.052 & 84.1 \\
\hline Spring & 0.000 & n.c. & 0.044 & 0.067 & -0.025 & 0.032 & 0.121 & 78.6 \\
\hline Autumn & 0.000 & n.c. & 0.059 & 0.094 & -0.084 & 0.038 & 0.117 & 82.9 \\
\hline Winter & 0.000 & 0.068 & n.c. & 0.097 & 0.034 & 0.030 & 0.073 & 78.3 \\
\hline \multicolumn{9}{|c|}{ TGM at $2 \mathrm{~m}$ height } \\
\hline Summer & -0.035 & -0.101 & 0.144 & -0.236 & -0.139 & -0.052 & -0.197 & 82.4 \\
\hline Spring & -0.002 & -0.114 & -0.108 & -0.345 & -0.065 & -0.085 & -0.282 & 81.6 \\
\hline Autumn & -0.008 & 0.242 & 0.038 & -0.269 & -0.079 & -0.125 & -0.390 & 84.5 \\
\hline Winter & 0.000 & -0.120 & -0.088 & -0.287 & 0.158 & -0.027 & 0.307 & 79.3 \\
\hline
\end{tabular}


The identification of wind speed as a primary factor in the lower gradient in autumn is consistent with the $\mathrm{Hg}$ exchange found at dusk in this period (Fig. 3). Wind speed is also important in the upper gradient in winter, i.e. the sector where the exchange of $\mathrm{Hg}$ is appreciable in Fig. 3.

\subsection{Horizontal profiles}

Profile 1 (Fig. 5a) represents the longest transect (12350 m), and it includes two Valdeazogues River cross-cuts: one near the El Entredicho open-pit mine (located $2500 \mathrm{~m}$ upstream) and the other at the beginning of the transect $(10800 \mathrm{~m}$ downstream from El Entredicho). Higher GEM contents were found in summer and spring, especially in the Valdeazogues River cross-cut closest to El Entredicho. In terms of data variability, transition seasons (spring and autumn) show the highest differences between maximum and minimum GEM concentrations, while winter presents the lowest. This data variability reaches its maximum amplitude in anomalous values (up to $60 \mathrm{ng} \mathrm{m}^{-3}$ during summer and spring near the MMP). Furthermore, data variability shows clear differences in background values between seasons, i.e. highest for transition seasons and lowest for summer and winter. Background levels are close to $6 \mathrm{ng} \mathrm{m}^{-3}$ during all seasons except for spring, which gave a value of $13 \mathrm{ng} \mathrm{m}^{-3}$. Springtime is characterized in Almadenejos by a marked increase in temperature and solar radiation (Fig. 2) compared with previous winter months, and an intense soil moisture release occurs that could enhance soil mercury emissions through the volatilization of more labile soil mercury species (Llanos et al., 2011). This process significantly increases the extent of higher background GEM levels, thus increasing the area directly affected by mercury emissions to more than $4 \mathrm{~km}$, taking into consideration the distance in profile 1 (Fig. 5a) from the Valdeazogues River to the MMP.

Profile 2 passes through minor and major mercury sources in the studied area, namely an abandoned metallurgical precinct (MMP), a closed underground mine (NCM) and two points with contaminated roads (CR in Fig. 5b). The maximum GEM concentrations were found during spring months, especially in proximity to the MMP and NCM, and the lowest concentrations were measured during winter months (Fig. 5b). The extent of the anomalous high values reaches maximum distances in summer, with higher data variability along the transect and minimum distances in winter when anomalous values appear within the background values.

Profile 3 represents the local background profile and crosses only one minor GEM source, the Valdeazogues River, $5000 \mathrm{~m}$ downstream from the El Entredicho mine (Fig. 5c). Maximum levels and variability in this transect were observed during autumn months, while winter represents the minimum for these two aspects. Background values were slightly lower $\left(4-5 \mathrm{ng} \mathrm{m}^{-3}\right)$ for each season considered when compared to those for profile 1 , although this profile represents a low-grade contaminated area in the min- ing district, with mercury present in sediments of the Valdeazogues and Rivera de Gargantiel rivers (García-Ordiales et al., 2016), in soils (Rodríguez et al., 2003), and incorporated into the road as polluted waste from the El Entredicho closure works.

The Valdeazogues River represents a strip of contaminated materials (Garcia-Ordiales et al., 2018) that comprises the alluvial plain, and it is probably the most important minor source of GEM in the region. This river crosses the district for $30 \mathrm{~km}$ from the easternmost $\mathrm{Hg}$ mine (El Entredicho) to the confluence with the Guadalmez River outside the mining district. The GEM levels for all seasons in a section of the Valdeazogues River mainly affected by El Entredicho waste are represented in Fig. 6, and it can be seen that the GEM average and range decrease with increasing distance from the mine.

The profile dataset was represented as lognormal distribution curves (Fig. 7) in an effort to determine the evolution of the main GEM sources in the studied area. The idea behind these graphs was to separate dataset populations, with the $y$ axis representing cumulative Gaussian distributions. The changes in the slope of each probabilistic curve (breaks) mark the boundaries between subpopulations. Profile 1 shows clear differences between "classic" seasons and "transition" seasons in terms of limits between normal and anomalous populations. In this sense, in summer and winter there is a break between normal and transitional populations at similar levels $\left(6.76 \mathrm{ng} \mathrm{m}^{-3}\right.$ in winter and $7.73 \mathrm{ng} \mathrm{m}^{-3}$ in summer), while in spring this break occurs at higher levels $\left(14.81 \mathrm{ng} \mathrm{m}^{-3}\right)$ and in autumn it occurs at $10.36 \mathrm{ng} \mathrm{m}^{-3}$. In profile 1 the anomalous population corresponds to emissions of Valdeazogues riverbank sediments, and these are detectable at $\mathrm{Hg}$ levels of $10 \mathrm{ng} \mathrm{m}^{-3}$ in drier seasons (autumn and summer) and up to $30.14 \mathrm{ng} \mathrm{m}^{-3}$ in wet seasons (winter and spring); it should be remembered that this profile does not have any significant emission sources, except for polluted sediments, and the background values are below $10-14 \mathrm{ng} \mathrm{m}^{-3}$ in all seasons. A scenario in which emission sources are absent is best represented by profile 3 , since it only has two points of contact with contaminated sediments ( $3.5 \mathrm{~km}$ away from the nearby El Entredicho mine), and therefore its total $\mathrm{Hg}$ contents are much lower than in profile 1 . Normal values appear in profile 3 at around $5 \mathrm{ng} \mathrm{m}^{-3}$ in summer and winter and at around $10 \mathrm{ng} \mathrm{m}^{-3}$ in spring and autumn. These values can be considered the local geochemical background values for the study area. It should be noted that a second transition population appears in autumn and winter, and this does not have an obvious explanation based on the appearance of a second source of emissions in this background value profile.

Profile 2 has two emission sources of medium importance and one of high importance that produce an increase in the limit values of the normal population (around $15 \mathrm{ng} \mathrm{m}^{-3}$ in all seasons except winter, which has a value of $8.6 \mathrm{ng} \mathrm{m}^{-3}$ ). This scenario with multiple emission sources leads to the ap- 
PROFILE 1
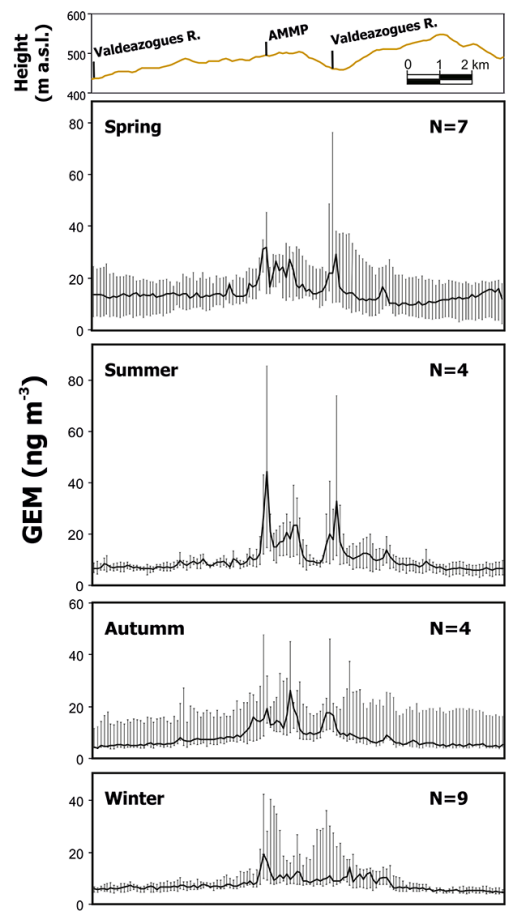

PROFILE 2

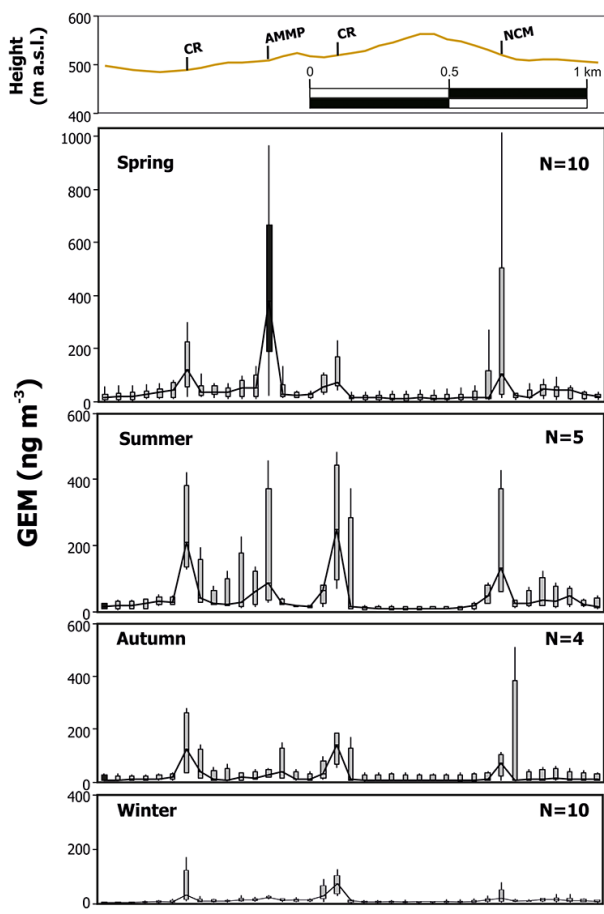

PROFILE 3
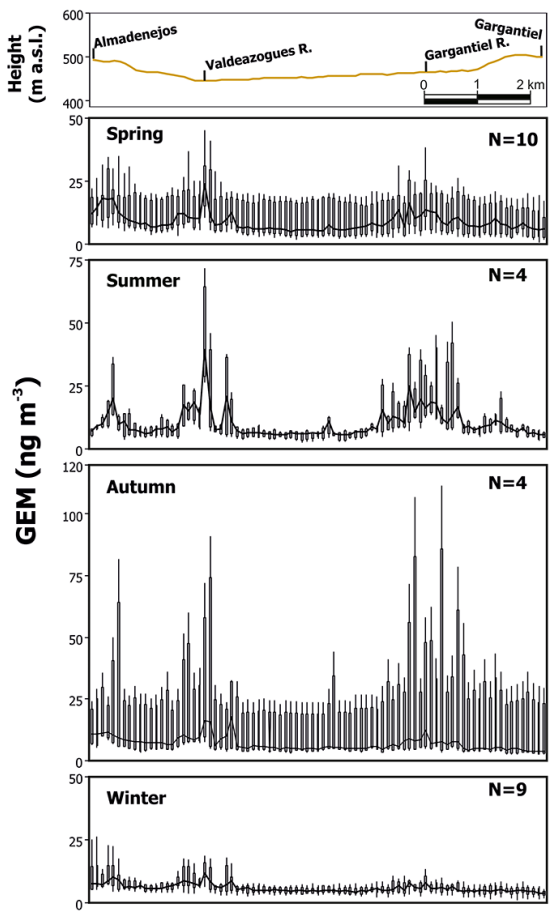

Figure 5. Box plot of GEM in the horizontal profiles along the Almadenejos area. Each box represents the average of $100 \mathrm{~m}$. The location of these profiles is shown in detail in Fig. 1.

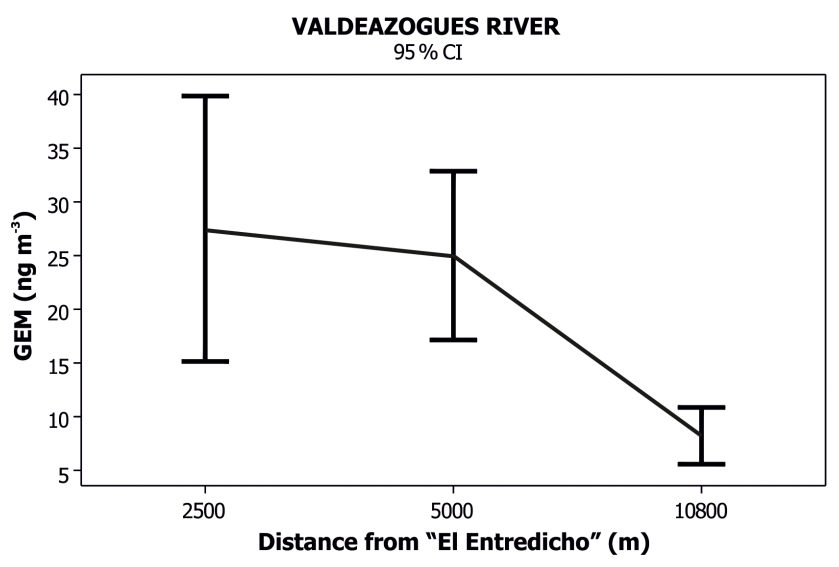

Figure 6. Variability in GEM levels on cross-cuts of the Valdeazogues River according to distance from the El Entredicho mine.

pearance of a second transition population in winter, autumn and summer. The existence of an emission source as important as the MMP produces an increase in the limit of anomalous values from around $70 \mathrm{ng} \mathrm{m}^{-3}$ in winter and spring to $243 \mathrm{ng} \mathrm{m}^{-3}$ in summer, i.e. well above the WHO (2000) limit for chronic exposure of $200 \mathrm{ng} \mathrm{m}^{-3}$.

All datasets measured for these three profiles correspond to a period (11:00-14:00 CET) of stability in terms of micrometeorological parameters, i.e. in the middle of the day. This approach is essential to ensure the comparability of the different transects, but it is a limitation in the temporal evolution of GEM contents throughout the day. The present work complements these daytime measurements with night-time ones based on the daily evolution described in the area (Esbrí et al., 2016; Tejero et al., 2015), but it should be mentioned that there is an alternative of carrying out these monitoring tasks using passive samplers (McLagan et al., 2018), which offer a greater time range. Their use as a substitute for direct measurements or in combination with them will undoubtedly result in higher representativeness of the data obtained. Night-time measurements during summer nights reveal higher GEM levels in the surroundings of mining-related GEM sources, with levels more than 2 times higher in Almadén, for instance. The present study provides information about the extent of this increase in nocturnal GEM levels. The evolution of $\mathrm{Hg}$ contents at three different time points, during the day when the wind ceases, and the probabilistic graph for each dataset are presented in Fig. 8. In profile 2 the maximum values are observed at the end of the monitoring, after the cessation of the wind, in all of the sources considered except for a contaminated road. This finding indicates that the wind is a determining factor for the increase in environmental concentrations of $\mathrm{Hg}$ despite the fact that the emissions are probably lower. The evolution of the increase in GEM values from the beginning to the end is difficult to observe in the distance vs. GEM graph, but the Lepeltier graph (Fig. 8b) offers a better view of the situation for all of the 
PROFILE 1
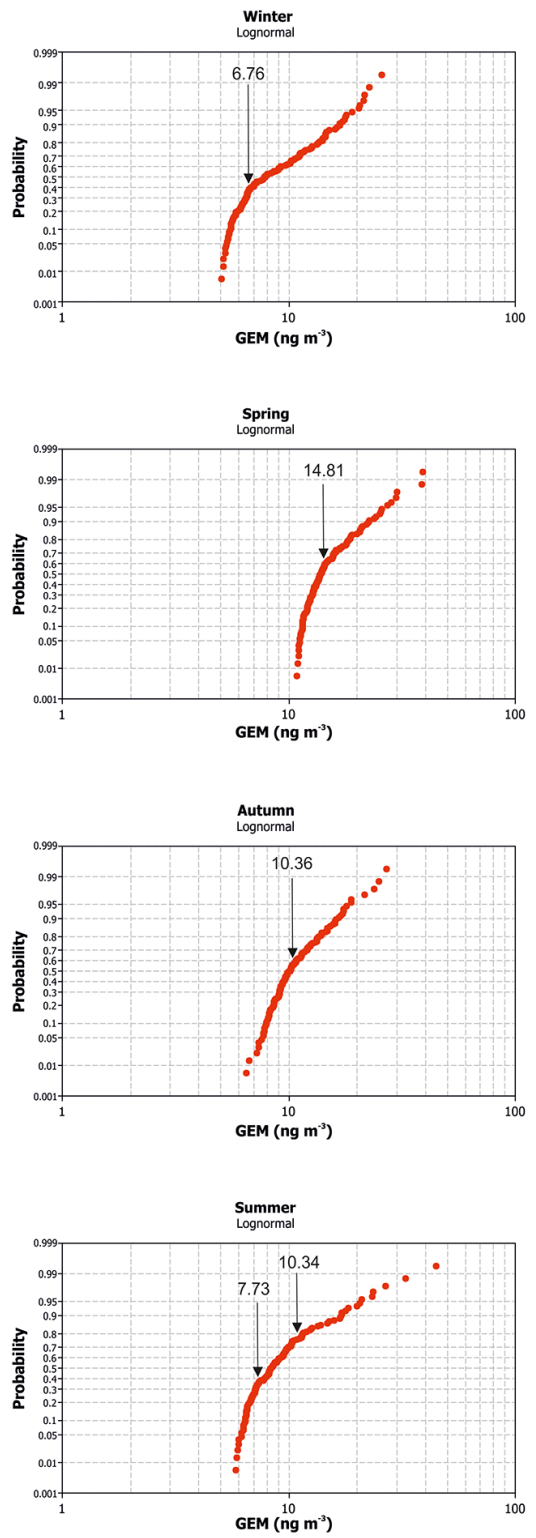

PROFILE 2
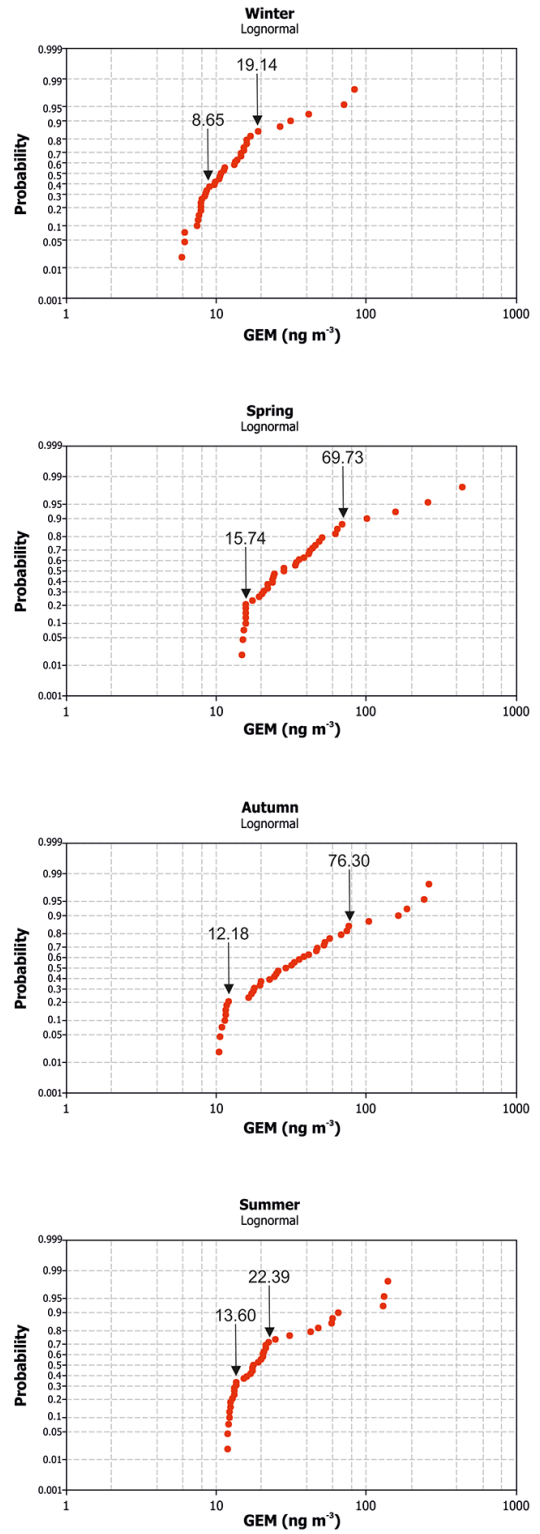

PROFILE 3
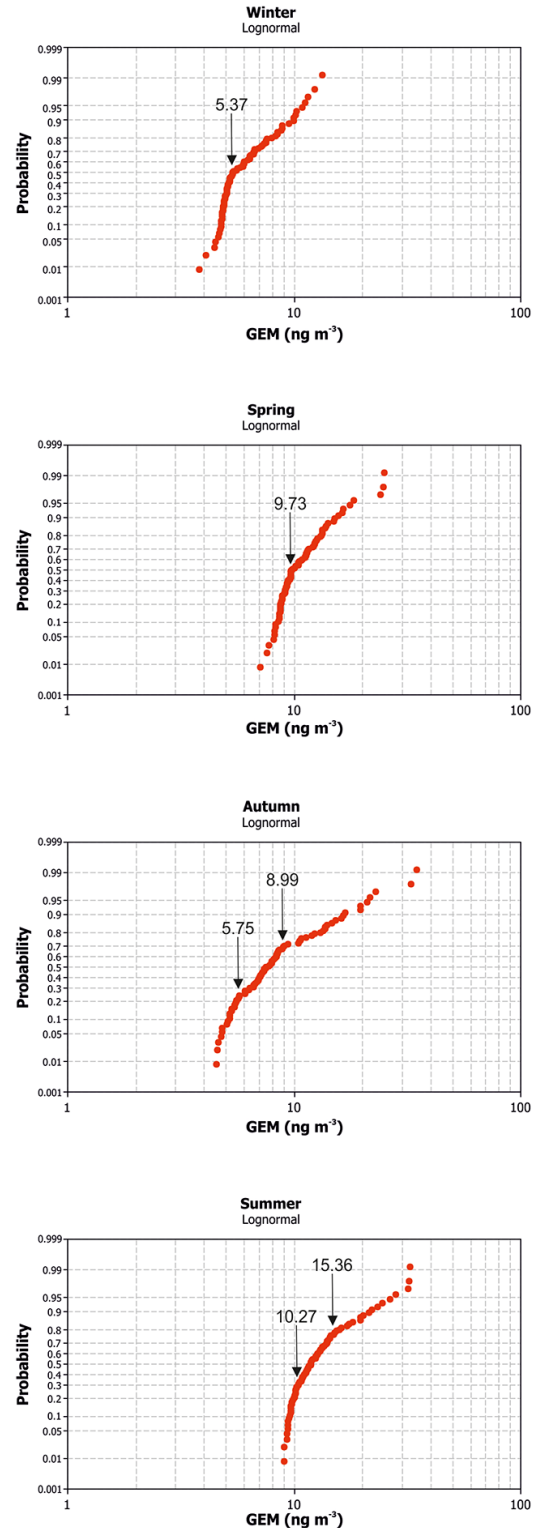

Figure 7. Lepeltier graphs for each profile according to the season.

data populations. In profile 2 the shift towards higher GEM values occurs only in the transition population and not in normal or anomalous values. The reason for this increase in the medium values (transition population) but not in normal or anomalous populations could be explained by the absence of dispersion processes, with background values and anomalous values remaining at similar levels because they are more dependent on emission factors (essentially temperature). So, what happens in profiles that do not have important emission sources? In profile 3 there are clearer increases towards the end of the monitoring without exception, and the increases in GEM contents affect all populations, i.e. normal, transi- tional and anomalous data. This trend provides evidence that the nocturnal increase in GEM values is homogeneous in the absence of significant sources of high emissions and only the topography seems to be an important factor that drives this process, as can be seen in Fig. 8c: gaseous mercury emitted by minor sources tends to move downslope and becomes more dilute during this dispersion process. It is necessary to emphasize that the topography of the study area consists of mountainous alignments of smooth slopes, typical of the Appalachian relief, with maximum height differences of $220 \mathrm{~m}$. In the case of profile 3, this accumulation process happens in the bottom of the valleys. The Valdeazogues River and its 
sediments are a minor $\mathrm{Hg}$ source, and the extent of higher nocturnal GEM levels reaches more than $1000 \mathrm{~m}$ around the riverbed through a combination of both accumulation process, i.e. local emissions from sediments and topography.

\subsection{D dispersion of TGM in the Almadenejos area}

The preliminary conclusions from the monitoring work on the vertical and horizontal gradients suggest that dilution processes are the key to explaining the movements of $\mathrm{Hg}$ in a mining-metallurgical environment with multiple emission sources scattered throughout the study area. The creation of the mixing layer in the early morning hours represents an increment in $\mathrm{Hg}$ dilution, and this is driven by increases in solar radiation, temperature and winds, which simultaneously lead to enhanced mercury emissions due to the same factors (Carpi and Lindberg, 1997; Gustin et al., 2002; Lindberg et al., 1999). Major gaseous Hg sources act as a constant supplier to the mixing layer, thus promoting movements to the closest areas and the deposition of this mercury when the convective forces cease and the mixing layer disappears. In terms of risk assessment, the mixing layer dilutes gaseous mercury and prevents the appearance of TGM levels up to $200 \mathrm{ng} \mathrm{m}^{-3}$ in populated areas, thus restricting the zone affected to some tens of metres, even with a huge gaseous mercury source (MMP) very close to the houses in Almadenejos. Conversely, this process causes the dispersion of a large amount of mercury to the surroundings, and this increases the risk of air-plant transfer, even to edible vegetables grown in local orchards. The most favourable seasons to activate this process are the driest and warmest (i.e. spring and summer), while the micrometeorological conditions that can inhibit this process are rain, regional winds or persistent fog on winter days.

An opposite scenario occurs when local winds cease in twilight hours: emission rates decline with the absence of solar radiation and the decrease in temperature, while a wind speed close to zero produces an increase in TGM concentrations and strong negative gradients (Fig. 2) at human heights (from 0 to $3 \mathrm{~m}$ above the ground). Once again, summer is the season that has the most negative gradients, and this is due to the contrasting differences in micrometeorological parameters (Fig. 2). During these nocturnal hours, horizontal movements play the most important role in the transference of gaseous mercury in the area. Clear differences in processes between diurnal and nocturnal hours can be highlighted: dispersion-diffusion, dilution-concentration and the predominance of vertical-horizontal transferences. As a consequence, the extent of the areas affected by higher TGM levels increases, and it is not only the well-known major sources that play an important role, but also minor sources, which produce extended areas with more than $200 \mathrm{ng} \mathrm{m}^{-3}$ during summer nights without winds. Contaminated sediments of the Valdeazogues River act as the main secondary source in the Almadenejos area. This river receives polluted fine- grained mine materials, particularly from the El Entredicho mine (Fig. 1) but also from other nearby old mines such as Las Cuevas, Vieja Concepción and Nueva Concepción.

In terms of risk assessment, the monitoring strategy presented in this work was able to identify the main zones of the urban area that can reach TGM concentrations above the WHO limit for chronic exposure $\left(200 \mathrm{ng} \mathrm{m}^{-3}\right)$ and also the period of time during the day or throughout the year in which this limit is exceeded. The vertical gradient dataset obtained in the immediate vicinity of a medium emission source (AWTP) seems to indicate that, in terms of average values, only the night-time periods in summer and autumn produce concentrations above the WHO limit. To identify the hours during which inhalation of gaseous $\mathrm{Hg}$ may occur, one must take into account the whole dataset and not only these average values. Likewise, we identified the most favourable conditions for the WHO limit for chronic exposure to be exceeded (Table 4). This was achieved using the MLRA equations for the dataset at $2 \mathrm{~m}$ (Table 3), i.e. the approximate height of a human being. It can be seen from the results in Table 4 that the nights are riskier than the days in all seasons ( $54 \%$ in spring and winter, $72 \%$ in summer), but in autumn this trend is reversed, with $99 \%$ of the hours of risk occurring during the day. The main factors are those related to dilution (or its absence): wind speed and solar radiation at null levels. It should be noted that the temperature in the hours of risk for inhalation of gaseous $\mathrm{Hg}$ can be as low as $-4{ }^{\circ} \mathrm{C}$ in winter, which is consistent with the idea expressed above that it is the dilution processes (or their absence) that most decisively influence in the creation of periods of risk for the inhalation of gaseous $\mathrm{Hg}$.

Once we had identified the micrometeorological conditions in which there was a risk, we proceeded to identify the extent of this risk in space. Profile 2 shows that the extent of the area affected by an emission source is independent of its importance in terms of absolute emissions, with the area not extending during the daytime period beyond $100 \mathrm{~m}$ from the location of the source (Fig. 5). In the night, however, the extent of the affected area can reach more than $200 \mathrm{~m}$ around the emission source (Fig. 8). Likewise, it can be seen from profile 3 (Fig. 8) that the risk associated with the increase in TGM values as a result of emissions of contaminated sediments from the Valdeazogues River is null, with values of $100 \mathrm{ng} \mathrm{m}^{-3}$ not exceeded even under the worst micrometeorological conditions: i.e. summer nights without wind. The displacement of the Lepeltier curves in Fig. 8 shows that the cessation of wind during the night produces an increase of up to $33 \mathrm{ng} \mathrm{m}^{-3}$ in the population of anomalous values, with only three values exceeding the WHO limit of $200 \mathrm{ng} \mathrm{m}^{-2}$, while in profile 2 this increase reaches $178 \mathrm{ng} \mathrm{m}^{-3}$, and, in this case, the micrometeorological conditions prevalent at night mean that almost all of the anomalous population exceeds the WHO limit of $200 \mathrm{ng} \mathrm{m}^{-3}$.

From the data discussed above one can estimate the extent of the risk areas in a basic way from the micrometeorologi- 

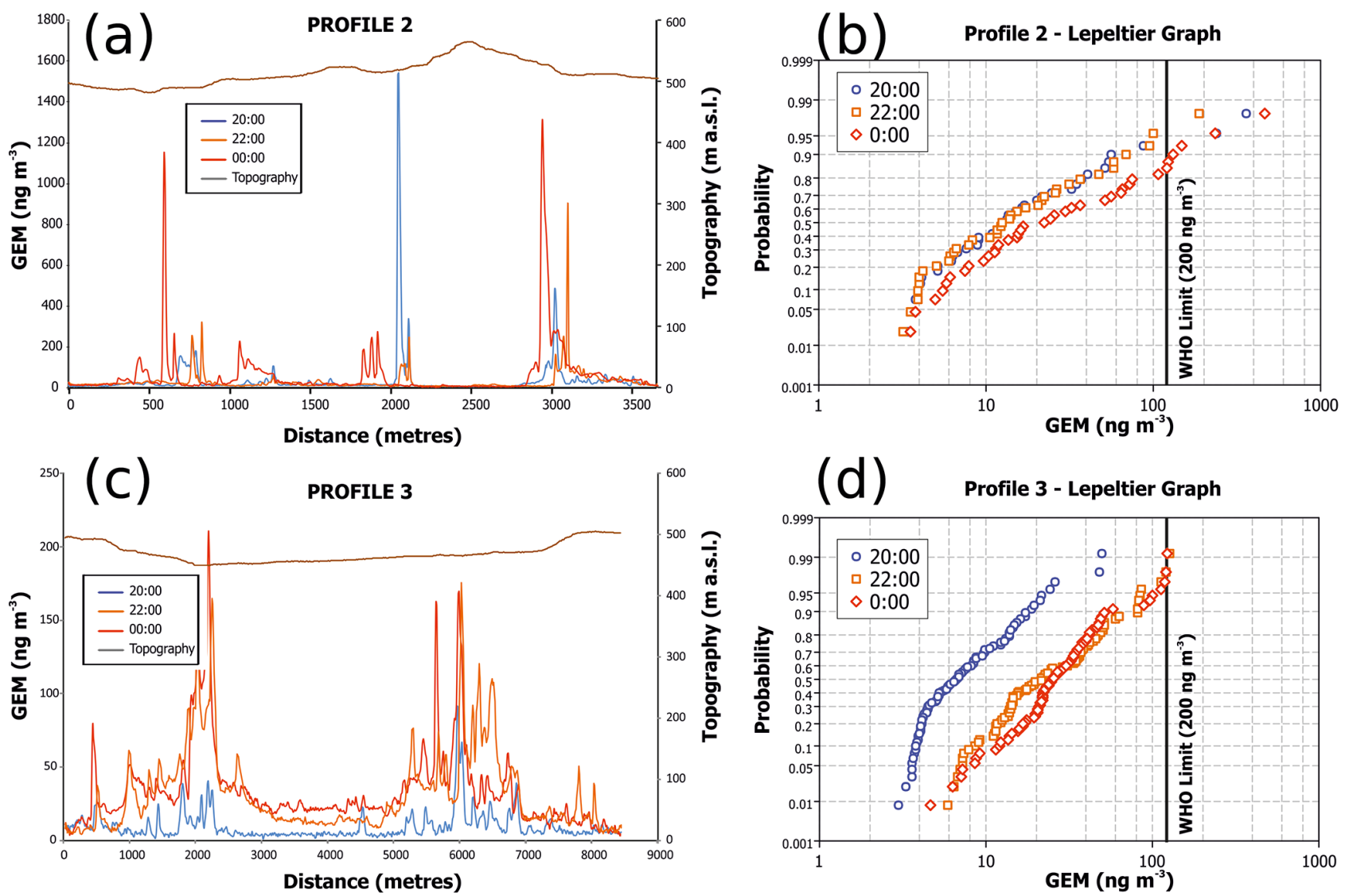

Figure 8. Nocturnal GEM levels in Almadenejos and surroundings. Summer average represents the average of diurnal GEM measurements in summer surveys. Panels (b) and (d) are the Lepeltier curves of datasets in panels (a) and (c), respectively.

Table 4. Micrometeorological conditions for TGM outdoor values to exceed the WHO limit for chronic exposure of $200 \mathrm{ng} \mathrm{m}^{-3}$. Abbreviations: $T$ : temperature; RH: relative humidity; WindSp: wind speed; and SR: solar radiation.

\begin{tabular}{llrrrrr}
\hline \multirow{2}{*}{ Summer } & Night & $\begin{array}{r}T\left({ }^{\circ} \mathrm{C}\right) \\
\mathrm{min}\end{array}$ & $\begin{array}{r}\mathrm{RH}(\%) \\
\min \end{array}$ & $\begin{array}{r}\text { WindSp }\left(\mathrm{m} \mathrm{s}^{-2}\right) \\
\max \end{array}$ & $\begin{array}{r}\mathrm{SR}\left(\mathrm{W} \mathrm{m}^{-2}\right) \\
\max \end{array}$ & $\begin{array}{r}\text { Time (h) } \\
\end{array}$ \\
& Day & 10.5 & 33.5 & 1.9 & 0 & 204 \\
\hline \multirow{2}{*}{ Autumn } & Night & 22.8 & & 1.7 & 0.2 & 93 \\
& Day & 7.8 & & 0 & 0 & 3 \\
\hline \multirow{2}{*}{ Winter } & Night & -4.1 & & 3.4 & 0.5 & 280 \\
& Day & -4.2 & & 0.3 & 0 & 155 \\
\hline \multirow{2}{*}{ Spring } & Night & 7.7 & & 0.1 & 0.2 & 19 \\
& Day & 9.5 & & 1.3 & 0 & 155 \\
& & & & 2.3 & 0.2 & 85 \\
\hline
\end{tabular}

cal conditions. Two extreme cases for day and night, in summer and in the absence of wind, are represented in Fig. 9. It can be observed that during the night the affected area can reach almost $100 \%$ of the homes in Almadenejos, although it is necessary to remember that the results of the MLRA indicated that only $11.34 \%$ of the hours of the studied year presented a risk of exceeding the WHO limit for chronic exposure $\left(200 \mathrm{ng} \mathrm{m}^{-3}\right)$.

This approach is applicable with little variation to any area affected by diffuse $\mathrm{Hg}$ emissions but will require adaptations if $\mathrm{Hg}$ emissions are active, whether they are anthropogenic (mostly industrial) or natural (volcanic related). In these cases, monitoring procedures must be extended to the 

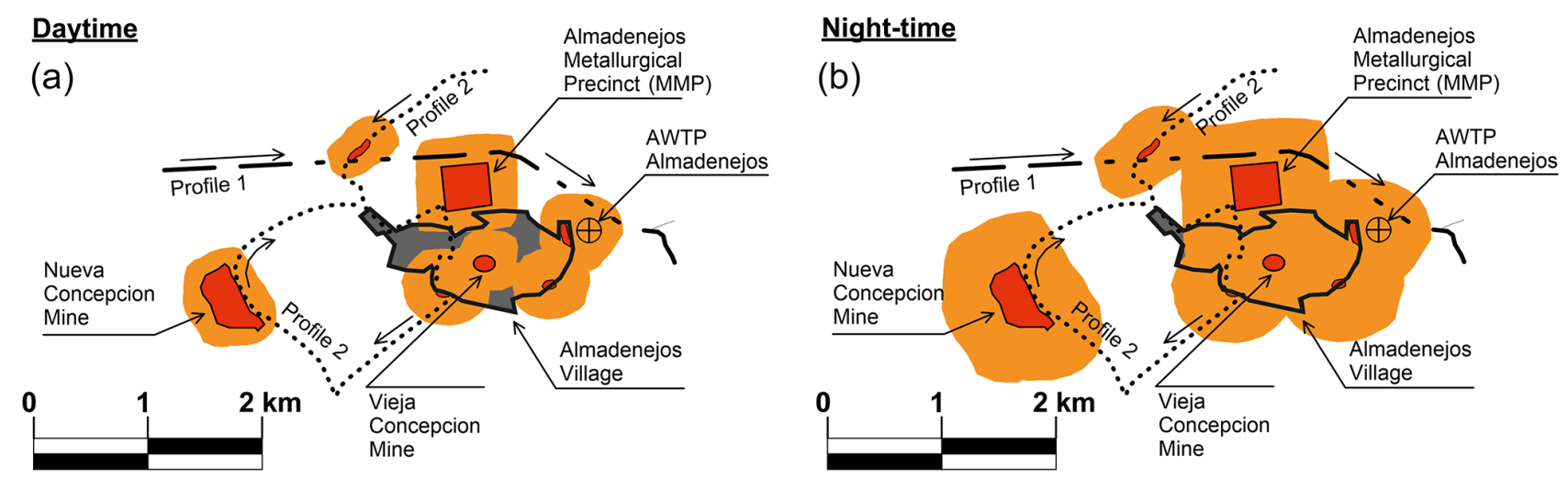

Figure 9. Extent of areas with $\mathrm{Hg}$ inhalation risk in the worst scenarios (orange) in relation to the different source areas (red) during daytime (a) and night-time (b).

emission processes with the aim of incorporating these data into the built model. In this way, the model will also serve to foresee changes in emission rates, either due to changes in technology in industrial activity, due to changes in emission patterns in natural processes or changes in emissions rates derived from restrictions of the Minamata Convention.

\section{Conclusions}

The study of transfer pathways of gaseous mercury in a mining-related environment has shown higher TGM levels at lower heights during nocturnal hours, relatively homogeneous and low levels during diurnal hours, and brief inversion periods during dawn and dusk.

Major sources act as constant suppliers of gaseous mercury to the diurnal mixing cell, while minor sources play an important role in mercury dispersion during nocturnal hours.

Vertical transferences occur preferentially during diurnal hours, while horizontal transferences predominate during nocturnal hours.

The monitoring strategy provided sufficient data to delineate spatial and temporal risk areas. This monitoring work established the following as minimum data to be obtained in any given area affected by gaseous $\mathrm{Hg}$ emissions:

- identification of emission sources, with special emphasis on location and importance;

- collection of data in a vertical transect at a fixed point during all seasons of the year; and

- collection of GEM data in horizontal transects that may include a combination of background and anomalous GEM values in its path, as well as day and night values.

A significant statistical treatment must be added to this TGM data acquisition strategy. It is proposed here that models should be established using MLRA in order to allow the estimation of the times of risk based on past or expected micrometeorological data, without the need to remeasure after performing the risk assessment.

The results of this risk assessment show that nights are riskier than days in all seasons (54\%-72\% in winter, spring and summer), but in autumn $99 \%$ of the higher-risk hours are diurnal. The main factors involved in the creation of periods of risk are those related to dilution (or its absence), e.g. wind speed and solar radiation at null levels. The extent of the affected area is independent of the importance of the source in terms of absolute emissions, with the affected area not extending more than $100 \mathrm{~m}$ away from the location of the source during the daytime period and $200 \mathrm{~m}$ in the nighttime. The worst scenario produced an affected area that covered almost the entire town of Almadenejos, although these risk conditions only represent $11.34 \%$ of the hours in an annual period.

Data availability. Research data are available to the scientific community on the basis of a justified request to secretaria.igea@uclm.es (Instituto de Geología Aplicada - UCLM).

Author contributions. The paper was written through contributions of all authors. JME and RN acquired all experimental data. JME and AMC applied MLRA to the dataset. JME, PLH and AMC produced the probabilistic Lepeltier graphs. All co-authors contributed to the writing of the paper.

Competing interests. The authors declare that they have no conflict of interest.

Special issue statement. This article is part of the special issue "Research results from the 14th International Conference on Mercury as a Global Pollutant (ICMGP 2019), MercOx project, and iGOSP 
and iCUPE projects of ERA-PLANET in support of the Minamata Convention on Mercury (ACP/AMT inter-journal SI)". It is not associated with a conference.

Acknowledgements. We thank the town hall of Almadenejos (Ciudad Real) for allowing the use of their wastewater treatment plant. Neil Thompson revised the English style in an early version of the paper.

Financial support. This research has been supported by the Spanish Ministry of Economy and Competitiveness (grant nos. CTM2012-33918 and CGL2015-67644-R).

Review statement. This paper was edited by Ashu Dastoor and reviewed by three anonymous referees.

\section{References}

Campos, J. A., Esbrí, J. M., Madrid, M. M., Naharro, R., Peco, J., García-Noguero, E. M., Amorós, J. A., Moreno, M. M., and Higueras, P.: Does mercury presence in soils promote their microbial activity? the Almadenejos case (Almadén mercury mining district, Spain), Chemosphere, 201, 799-806, 2018.

Carpi, A. and Lindberg, S. E.: Sunlight-mediated emission of elemental mercury from soil amended with municipal sewage sludge, Environ. Sci. Technol., 31, 2085-2091, 1997.

Deng, C., Xie, H., Ye, X., Zhang, H., Liu, M., Tong, Y., Ou, L., Yuan, W., Zhang, W., and Wang, X.: Mercury risk assessment combining internal and external exposure methods for a population living near a municipal solid waste incinerator, Environ. Pollut., 219, 1060-1068, 2016.

Eckley, C. S., Gustin, M., Miller, M. B., and Marsik, F.: Scaling non-point-source mercury emissions from two active industrial gold mines: Influential Variables and Annual Emission Estimates, Environ. Sci. Technol., 45, 392-399, 2011.

Esbrí, J. M., López-Berdonces, M. A., Fernández-Calderón, S., Higueras, P., and Díez, S.: Atmospheric mercury pollution around a chlor-alkali plant in Flix (NE Spain): An integrated analysis, Environ. Sci. Pollut. Res., 22, 4842-4850, 2015.

Esbrí, J. M., Martínez-Coronado, A., and Higueras, P. L.: Temporal variations in gaseous elemental mercury concentrations at a contaminated site: Main factors affecting nocturnal maxima in daily cycles, Atmos. Environ., 125, 8-14, 2016.

Esbrí, J. M., Cacovean, H., and Higueras, P.: Usage proposal of a common urban decorative tree (Salix alba L.) to monitor the dispersion of gaseous mercury: A case study from Turda (Romania), Chemosphere, 193, 74-81, 2018a.

Esbrí, J. M., Izquierdo, C., Martínez-Coronado, A., Miteva, I., and Higueras, P. L.: Particulate matter and particulate-bound mercury in a heavily polluted site related to ancient mining and metallurgy: A proposal for dry deposition modeling based on micrometeorological conditions, Environ. Sci. Pollut. Res., 25, 3531235321, 2018b.

Fernández-Patier, R. and Ramos-Díaz, M. C.: Informe del Ejercicio de lntercomparación de Mercurio Gaseoso total en aire ambiente
"IN SITU" (año 2011). Ined. Repport, Instituto de Salud Carlos III, Centro Nacional de Sanidad Ambiental, Área de Contaminación Atmosférica, Ministerio de Economía y Competitividad, España, 2011.

Ferrara, R., Maserti, B. E., Anderson, M., Edner, H., Ragnarson, P., Svanberg, S., and Hernandez, A.: Atmospheric mercury concentrations and fluxes in the Almaden district (Spain), Atmos. Environ., 32, 3897-3904, 1998.

Fu, X., Zhu, W., Zhang, H., Sommar, J., Yu, B., Yang, X., Wang, X., Lin, C.-J., and Feng, X.: Depletion of atmospheric gaseous elemental mercury by plant uptake at Mt. Changbai, Northeast China, Atmos. Chem. Phys., 16, 12861-12873, https://doi.org/10.5194/acp-16-12861-2016, 2016.

García-Ordiales, E., Covelli, S., Esbrí, J. M., Loredo, J., and Higueras, P. L.: Sequential extraction procedure as a tool to investigate PTHE geochemistry and potential geoavailability of dam sediments (Almadén mining district, Spain), Catena, 147, 394-403, 2016.

Garcia-Ordiales, E., Higueras, P., Esbrí, J. M., Roqueñí, N., and Loredo, J.: Seasonal and spatial distribution of mercury in stream sediments from Almadén mining district, Geochem. Explor. Environ. Ana., 19, 121-128, 2018.

Guan, Z. G., Lundin, P., Mei, L., Somesfalean, G., and Svanberg, S.: Vertical Lidar sounding of atomic mercury and nitric oxide in a major Chinese city, Appl. Phys. B, 101, 465-470, 2010.

Gustin, M. S., Biester, H., and Kim, C. S.: Investigation of the light-enhanced emission of mercury from naturally enriched substrates, Atmos. Environ., 36, 3241-3254, 2002.

Higueras, P., Oyarzun, R., Lillo, J., Sánchez-Hernández, J. C., Molina, J. A., Esbrí, J. M., and Lorenzo, S.: The Almadén district (Spain): Anatomy of one of the world's largest hg-contaminated sites, Sci. Total Environ., 356, 112-124, 2006.

Higueras, P., María Esbrí, J., Oyarzun, R., Llanos, W., MartínezCoronado, A., Lillo, J., López-Berdonces, M. A., and GarcíaNoguero, E. M.: Industrial and natural sources of gaseous elemental mercury in the Almadén district (Spain): An updated report on this issue after the ceasing of mining and metallurgical activities in 2003 and major land reclamation works, Environ. Res., 125, 197-208, 2013.

Higueras, P., Oyarzun, R., Kotnik, J., Esbrí, J. M., MartínezCoronado, A., Horvat, M., López-Berdonces, M. A., Llanos, W., Vaselli, O., Nisi, B., Mashyanov, N., Ryzov, V., Spiric, Z., Panichev, N., McCrindle, R., Feng, X., Fu, X., Lillo, J., Loredo, J., García, M. E., Alfonso, P., Villegas, K., Palacios, S., Oyarzún, J., Maturana, H., Contreras, F., Adams, M., Ribeiro-Guevara, S., Niecenski, L. F., Giammanco, S., and Huremovic, J.: A compilation of field surveys on gaseous elemental mercury (GEM) from contrasting environmental settings in Europe, South America, South Africa and China: separating fads from facts, Environ. Geochem. Health., 36, 713-734, 2014.

ISO/IEC Guide 43-1: Proficiency Testing by Interlaboratory Comparisons Part 1: Development and Operation of Laboratory Proficiency Testing, available at: http://www.iso.org/iso/iso_ catalogue/catalogue_tc/catalogue_detail.htm?csnumber=27216 (last access: 18 March 2015), 1997.

Lepeltier, C.: A simplified statistical treatment of geochemical data by graphical representation, Econ. Geol., 64, 538-550, 1969.

Lindberg, S. E., Zhang, H., Gustin, M., Vette, A., Marsik, F., Owens, J., Casimir, A., Ebinghaus, R., Edwards, G., Fitzgerald, 
C., Kemp, J., Kock, H. H., London, J., Majewski, M., Poissant, L., Pilote, M., Rasmussen, P., Schaedlich, F., Schneeberger, D., Sommar, J., Turner, R., Wallschlager, D., and Xiao, Z.: Increases in mercury emissions from desert soils in response to rainfall and irrigation, J. Geophys. Res.-Atmos., 104, 21879-21888, 1999.

Llanos, W., Kocman, D., Higueras, P., and Horvat, M.: Mercury emission and dispersion models from soils contaminated by cinnabar mining and metallurgy, J. Environ. Monit., 13, 34603468, 2011.

Martínez-Coronado, A., Oyarzun, R., Esbrí, J. M., Llanos, W., and Higueras, P.: Sampling high to extremely high hg concentrations at the Cerco de Almadenejos, Almadén mining district (Spain): The old metallurgical precinct (1794 to 1861AD) and surrounding areas, J. Geochem. Explor., 109, 70-77, 2011.

Maxwell, J. A., Holsen, T. M., and Mondal, S.: Gaseous elemental mercury (GEM) emissions from snow surfaces in Northern New York, PloS One, 8, e69342, https://doi.org/10.1371/journal.pone.0069342, 2013.

McLagan, D. S., Mitchell, C. P. J., Steffen, A., Hung, H., Shin, C., Stupple, G. W., Olson, M. L., Luke, W. T., Kelley, P., Howard, D., Edwards, G. C., Nelson, P. F., Xiao, H., Sheu, G.-R., Dreyer, A., Huang, H., Abdul Hussain, B., Lei, Y. D., Tavshunsky, I., and Wania, F.: Global evaluation and calibration of a passive air sampler for gaseous mercury, Atmos. Chem. Phys., 18, 59055919, https://doi.org/10.5194/acp-18-5905-2018, 2018.

Naharro, R., Esbrí, J. M., Amorós, J. Á., García-Navarro, F. J., and Higueras, P.: Assessment of mercury uptake routes at the soilplant-atmosphere interface, Geochem.-Explor. Env. A., 19, 146154,2018

O’Driscoll, N. J., Beauchamp, S., Siciliano, S. D., Rencz, A. N., and Lean, D. R. S.: Continuous analysis of dissolved gaseous mercury (DGM) and mercury flux in two freshwater lakes in Kejimkujik Park, Nova Scotia: Evaluating mercury flux models with quantitative data, Environ. Sci. Technol., 37, 2226-2235, 2003.

Radke, L. F., Friedli, H. R., and Heikes, B. G.: Atmospheric mercury over the NE pacific during spring 2002: Gradients, residence time, upper troposphere lower stratosphere loss, and long-range transport, J. Geophys. Res.-Atmos., 112, D19305, https://doi.org/10.1029/2005JD005828, 2007.

Rodríguez, L., Lopez-Bellido, F. J., Carnicer, Á., and AlcaldeMorano, V.: Phytoremediation of mercury-polluted soils using crop plants, Fresenius Environ. Bull., 12, 967-971, 2003.

Saiz-Lopez, A., Plane, J. M. C., Mahajan, A. S., Anderson, P. S., Bauguitte, S. J.-B., Jones, A. E., Roscoe, H. K., Salmon, R. A., Bloss, W. J., Lee, J. D., and Heard, D. E.: On the vertical distribution of boundary layer halogens over coastal Antarctica: implications for $\mathrm{O}_{3}, \mathrm{HO}_{x}, \mathrm{NO}_{x}$ and the $\mathrm{Hg}$ lifetime, Atmos. Chem. Phys., 8, 887-900, https://doi.org/10.5194/acp-8887-2008, 2008.

Sizmur, T., McArthur, G., Risk, D., Tordon, R., and O'Driscoll, N. J.: Gaseous mercury flux from salt marshes is mediated by solar radiation and temperature, Atmos. Environ., 153, 117-125, 2017
Slemr, F., Weigelt, A., Ebinghaus, R., Bieser, J., Brenninkmeijer, C. A. M., Rauthe-Schöch, A., Hermann, M., Martinsson, B. G., van Velthoven, P., Bönisch, H., Neumaier, M., Zahn, A., and Ziereis, H.: Mercury distribution in the upper troposphere and lowermost stratosphere according to measurements by the IAGOS-CARIBIC observatory: 2014-2016, Atmos. Chem. Phys., 18, 12329-12343, https://doi.org/10.5194/acp-18-123292018, 2018.

Stamenkovic, J., Gustin, M. S., Arnone, J. A., Johnson, D. W., Larsen, J. D., and Verburg, P. S. J.: Atmospheric mercury exchange with a tallgrass prairie ecosystem housed in mesocosms, Sci. Total. Environ., 406, 227-238, 2008.

Steffen, A., Schroeder, W., Bottenheim, J., Narayan, J., and Fuentes, J. D.: Atmospheric mercury concentrations: Measurements and profiles near snow and ice surfaces in the Canadian Arctic during alert 2000, Atmos. Environ., 36, 2653-2661, 2002.

Tackett, P. J., Cavender, A. E., Keil, A. D., Shepson, P. B., Bottenheim, J. W., Morin, S., Deary, J., Steffen, A., and Doerge, C.: A study of the vertical scale of halogen chemistry in the arctic troposphere during polar sunrise at barrow, Alaska, J. Geophys. Res.-Atmos., 112, D07306, https://doi.org/10.1029/2006JD007785, 2007.

Tejero, J., Higueras, P., Esbrí, J. M., Garrido, I., Oyarzun, R., and Español, S.: An estimation of mercury concentrations in the local atmosphere of Almadén (Ciudad Real Province, South-Central Spain) during the 20th Century, Environ. Sci. Pollut. Res., 22, 4833-4841, 2015.

Vaselli, O., Higueras, P., Nisi, B., Esbrí, J., Cabassi, J., MartínezCoronado, A., Tassi, F., and Rappuoli, D.: Distribution of gaseous hg in the mercury mining district of Mt. Amiata (central Italy): A geochemical survey prior the reclamation project, Environ. Res., 125, 179-187, 2013.

Weigelt, A., Ebinghaus, R., Pirrone, N., Bieser, J., Bödewadt, J., Esposito, G., Slemr, F., van Velthoven, P. F. J., Zahn, A., and Ziereis, H.: Tropospheric mercury vertical profiles between 500 and $10000 \mathrm{~m}$ in central Europe, Atmos. Chem. Phys., 16, 41354146, https://doi.org/10.5194/acp-16-4135-2016, 2016.

WHO: Air Quality Guidelines for Europe, WHO Regional Publications European Series 91, World Health Organization Regional Office for Europe, Copenhagen 274 pp., available at: https://www.euro.who.int/_data/assets/pdf_file/0005/74732/ E71922.pdf (last access: 11 November 2019), 2000.

Zhu, W., Sommar, J., Lin, C.-J., and Feng, X.: Mercury vapor air-surface exchange measured by collocated micrometeorological and enclosure methods - Part I: Data comparability and method characteristics, Atmos. Chem. Phys., 15, 685-702, https://doi.org/10.5194/acp-15-685-2015, 2015.

Zhu, W., Lin, C.-J., Wang, X., Sommar, J., Fu, X., and Feng, X.: Global observations and modeling of atmosphere-surface exchange of elemental mercury: a critical review, Atmos. Chem. Phys., 16, 4451-4480, https://doi.org/10.5194/acp-164451-2016, 2016. 